\title{
Peran Public Relations di Industri Perhotelan
}

\author{
Ajeng Safira Rizki Amanda', Siti Salafiyah Hamidah², Rudi Rusdiana ${ }^{3}$, Fandi Muhammad ${ }^{4}$ \\ Prodi Ilmu Komunikasi, Fakultas IImu Komunikasi, Universutas Islam Nusantara
}

\begin{tabular}{|c|c|}
\hline ARTICLE INFO & ABSTRACT \\
\hline Article history: & This study aims to determine the role of Public Relations in the \\
\hline $\begin{array}{r}\text { Received Jan 03, } 2022 \\
\text { Revised Feb 23, } 2022 \\
\text { Accepted Maret 02, } 2022\end{array}$ & $\begin{array}{l}\text { hospitality industry in managing and maintaining the good image of the } \\
\text { hotel. The research instrument used in this research is the method of } \\
\text { observation at Grandia Hotel Bandung and giving questionnaires to the }\end{array}$ \\
\hline Keywords: & $\begin{array}{l}\text { method uses a qualitative approach by applying the type of descriptive } \\
\text { research, namely from the data that has been collected the researcher }\end{array}$ \\
\hline $\begin{array}{l}\text { Public Relation; } \\
\text { Industri perhotelan; } \\
\text { Komunikasi. }\end{array}$ & $\begin{array}{l}\text { tries to draw conclusions. Data analysis techniques include data } \\
\text { reduction, data decomposition, and drawing conclusions. The result of } \\
\text { this research is that public relations has a duty in shaping the good } \\
\text { image of the hotel to the public. With the existence of public relations, } \\
\text { the communication that exists is harmonious between the institution } \\
\text { and the public by creating good reciprocity. Public relations has two } \\
\text { important roles in a company, namely the regulatory function and the } \\
\text { supervisory function of a company. Public relations is a very important } \\
\text { part in the hospitality industry in creating an image for both internal and } \\
\text { external parties. The conclusion of this study is that public relations has } \\
\text { an important role in the hospitality industry, namely in creating a } \\
\text { positive image of the hotel to the public by maintaining the relationship } \\
\text { between the hotel and the public or with other companies becomes } \\
\text { more harmonious, and public relations also plays a role in supervising } \\
\text { an institution, providing advice and also providing the best solution in } \\
\text { solving a company problem. }\end{array}$ \\
\hline
\end{tabular}

\section{ABSTRAK}

Penelitian ini bertujuan untuk mengetahui peran Public Relation di dalam industri perhotelan dalam mengelola dan menjaga citra baik dari hotel tersebut. Instrumen penelitian yang digunakan dalam penelitian ini adalah metode observasi di Grandia Hotel Bandung dan memberikan kuesioner kepada staff dan Public Relation Grandia Hotel Bandung. Metode penelitian menggunakan pendekatan kualitatif dengan menerapkan jenis penelitian Deskriptif yaitu dari data yang sudah terkumpul peneliti berusaha menarik kesimpulan. Teknik analisis data meliputi reduksi data, penguraian data, dan penarikan kesimpulan. Hasil dari penelitian ini adalah bahwa public relation bertugas dalam membentuk citra baik hotel kepada publik. Dengan adanya publik relation menjadikan komunikasi yang terjalin menjadi harmonis antara lembaga dengan publik dengan menciptakan timbal balik yang baik. Public relation mempunyai dua peranan penting dalam suatu perusahaan yaitu fungsi pengaturan dan fungsi pengawasan suatu perusahaan. Public relation menjadi suatu bagian yang sangat penting didalam industri perhotelan dalam menciptakan citra baik kepada pihak internal maupun pihak eksternal.Kesimpulan dari penelitian ini adalah bahwa public relation memiliki peranan yang penting didalam industri perhotelan, yaitu dalam menciptakan image positive dari hotel kepada publik dengan cara menjaga hubungan antara hotel dengan publik atau dengan perusahaan lain menjadi lebih harmonis, serta public relation juga berperan dalam mengawasi suatu lembaga, memberikan nasehat dan juga memberikan solusi terbaik dalam memecahkan suatu masalah perusahaan. 


\section{Corresponding Author:}

Rudi Rusdiana

Prodi Ilmu Komunikasi, Fakultas IImu Komunikasi,

Universitas Islam Nusantara, Jawa Barat, Indonesia

Jl. Soekarno-Hatta No.530, Kota Bandung, Jawa Barat 40286

E-mail :rudirusdiana246@gmail.com

\section{PENDAHULUAN}

Peningkatan kunjungan wisatawan telah memberikan kemajuan dengan semakin banyaknya investor yang ingin melakukan investasi, khususnya yang berhubungan dengan kegiatan pariwisata dan juga akomodasi wisata seperti hotel, restaurant, café, travel agent dan sebagainya.Seperti yang kita ketahui, hotel merupakan salah satu akomodasi yang menyediakan jasa penginapan kepada tamu dengan dilengkapi berbagai fasilitas yang menunjang kepuasan tamu dengan tujuan komersial.Hotel adalah suatu bentuk usaha yang terdiri dari berbagai departemen yang saling membutuhkan dan saling bekerjasama dalam memberikan pelayanan yang memuaskan kepada tamu.

Adapun departemen-departemen tersebut adalah Front Office Department, Food \& Beverage Department, Housekeeping Department, Enginering Department, Security Department, Sales \& Marketing Department, Accounting Department, Personal Department. Food \& Beverage Department adalah departemen yang mempunyai tugas dan tanggung jawab terhadap penyediaan dan pelayanan makanan dan minuman terhadap tamu.Seperti yang diketahui bahwa selain penjualan kamar sebagaian sumber pendapatan utama hotel adalah dengan penjualan makanan dan minuman.

Salah satu Hotel trategis yang berada di Bandung yaitu, Grandia hotel yang terletak di jalan Cihampelas No 80-82. Hotel ini dekat dengan jembatan layang pasupati yang memberikan pemandangan dari rooftop untuk para tamu.Lokasi ini sangat memudahkan bagi pelancong untuk mencarinya. Hotel ini bisa ditempuh dari jalan Cihampelas atas atau jalan Cipaganti, dari persimpangan empat Pasteur tinggal belok kiri, kemudian belok kanan, hotel Grandia persis berada di sebelah kiri dari arah jalan Cihampelas. Lokasi Grandia Hotel ini tidak jauh dari Paris Van Java di jalan Sukajadi, jika tamu ingin berjalan jalan ke Dago dari hotel ini pun tidak terlalu jauh hanya 10 menit jika menggunakan kendaraan.Begitu juga ke jalan Martadinata tempat belanja clothing atau factory outlet dari hotel ini bisa ditempuh hanya dengan hitungan menit.Keuntungan menginap di hotel ini adalah lokasinya yang dekat dengan tempat favorite wisatawan yang berkunjung ke Bandung. Hotel ini dekat dengan Cihampelas Walk, kawasan bisnis yang menawarkan tempat belanja dan hiburan bagi para pengunjung, untuk ke Cihampelas dari hotel Grandia hanya butuh waktu 7 menit saja.

Hotel bintang 4 berlantai 10 ini menyediakan 86 kamar, dibagi menjadi 4 tipe kamar yakni, 75 kamar tipe Deluxe, 6 kamar tipe Deluxe Pool View, 2 kamar tipe Grandia Suite, dan 3 kamar tipe Family Suite. Keempat tipe kamar tersebut memiliki ukuran yang berbeda - beda, kamar tipe Deluxe memiliki ukuran 26 meter persegi, tipe Deluxe Pool View berukuran 29 meter persegi, tipe Grandia Suite berukuran 46 meter persegi, dan Family Suite memiliki ukuran 96 meter persegi. Setiap kamar memiliki fasilitas sebagai berikut, TV LCD 32inc yang memiliki chanel satellite, untuk koneksi ada jaringan WIFE, di kamar juga disediakan Air Conditioning, alat pembuat tea and coffee (coffee set), ruangan untuk merokok dan bagi yang tidak meroko.

Industry perhotelan merupakan salah satu yang bergerak dalam bidang pelayanan dan jasa juga turus memberikan masukan yang besar dalam sektor pariwisata. Public Relations kini menjadi salah satu tombak sektor industri untuk bersaing dalam era globasisasi ini, terutama dalam menciptakan suatu image positif untuk membangun pencitraan dalam suatu perusahaan. Media memiliki peran yang penting dalam menyampaikan berita dan fakta sebagai penyampai informasi dari beberapa pihak yang berkepentingan. Sejalan dengan perkembangan dunia ini sekarang bergerak kearah era globalisasi dimana batas antara ruang dan waktu bukan lagi menjadi 
penghalang bagi setiap orang untuk melakukan aktivitasnya baik bisnis maupun kesenangan (Nova, $2009: 24)$

Komunikasi pula yang membantu individu untuk memahami satu sama lain dan membina hubungan jangka panjang yang baik. Definisi dari komunikasi adalah Suatu proses dimana sumber mentransmisikan pesan kepada penerima melalui beragam saluran sebuah perusahaan, komunikasi yang baik dengan pihak stakeholder eksternal dan internal dengan menciptakan strategi komunikasi yang diterapkan secara terencana (Wiryanto, $2004: 6$ ). Apalagi melihat realitas meningkatnya pertumbuhan perusahaan saat ini sehingga memperketat persaingan pasar.Setiap perusahaan berusaha menampilkan citra atau image yang baik dimata masyarakat maupun internal stakeholder.Perusahaan yang mampu mempertahankan eksistensi dan merebut pasar dinilai memiliki keunggulan dan nilai lebih di masyarakat.Public Relations merupakan salah satu saluran berkomunikasi, komunikasi yang dilakukan oleh Public Relations mempunyai tujuan untuk menjalin dan menjaga hubungan baik dengan public internal dan ekternal.Hal itu terwujud didalam suatu perusahaan yang diwakilinya, komunikasi dilakukan untuk mewujudkan kepentingan perusahaan tersebut.

Public Relations adalah komunikasi dua arah antara suatu lembaga dengan publik dalam rangka menciptakan hubungan yang harmonis dengan melalui komunikasi saling timbal balik guna menciptakan saling pengertian kepada publik baik internal maupun eksternal.Public Relations berfungsi membina atau menjalin hubungan ke dalam, ke luar, mempromosikan dan mempublikasikan kegiatan lembaga sebagai nilai positif (Luqman, 2013).Publik dalam Public Relations yang dimaksud disini juga bukanlah hanya orang - orang dari luar organisasi (eksternal) tetapi juga orang - orang dari dalam organisasi (internal) misalnya para karyawan dari organisasi. Sebuah organisasi merupakan satu kesatuan dan sekumpulan individu dengan tujuan atau goal yang sama. Organisasi adalah perilaku simbolik dan eksistensinya bergantung pada makna bersama dan pada penafsiran yang diperoleh melalui interaksi manusia (Rohim, 2009). Public Relations adalah salah satu faktor yang berperan penting dalam suatu perusahaan karena memiliki fungsi manajemen untuk menjembatani dan membina hubungan yang saling menguntungkan antara pihak perusahaan dengan publiknya.Dalam pengertian tersebut tampak bahwa kegiatan Public Relations berada pada kata manajemen relasi dan komunikasi yang berujung pada terciptanya hubungan baik demi meningkatkan pencitraan individu atau perusahaan tersebut (Cutlip \& Center, 2006).Bagi seorang Public Relations, hubungan dengan berbagai publik melalui komunikasi yang efektif sangat penting untuk selalu dipelihara dan dibina dalam rangka menimbulkan pengertian bersama dan hubungan yang harmonis antara kedua belah pihak, yaitu organisasi dan publiknya (Herimanto, 2007 :11).

Dengan adanya publik relations kita bisa memanfaatkan sisi positif dan memberikan lowongan pekerjaan bagi masyarakat sekitar agar bisa menguntungkan satu sama lain dan tidak terjadinya pihak ketiga yang akan mempengaruhi citra industry hotel, dengan Sector industry parawisata adalah sebagai salah satu sumber untuk penciptaan lapangan kerja bagi masyarakat serta kesempatan berusaha, secara umum pembangunan adalah proses menuju suatu perubahan, pembangunan suatu daerah dipengaruhi beberapa sektor yang berkembang di daerah tersebut. Salah satunya adalah sektor yang berkembang tersebuat yaitu sektor parawisata. (Ghaniy Sanaubar, dkk, 2017).

\section{METODE PENELITIAN}

Metode penelitian yang digunakan dalam penelitian ini menggunakan pendekatan kualitatif dengan menerapkan jenis penelitian Deskriptif. Menurut Anggito \& Setiawan (2018)penelitian kualitatif merupakan sebuah metode pengumpulan data pada suatu latar alamiah dengan maksud menafsirkan fenomena yang terjadi dimana peneliti menjadi instrumen kunci pada penelitian tersebut.Peneliti mencoba menjelaskan atau menggambarkan suatu fenomena yang terjadi dengan mengumpulkan data dari sumber yang berkaitan dengan peristiwa tersebut. Lebih lanjut lagi Basri (2014) menyatakan bahwa fokus dari penelitian kualitatif adalah terletak pada proses dan pemaknaan hasilnya. 
Instrumen penelitian deskriptif yang digunakan adalah observasi, kuesioner dan studi pustaka.Adapun kuesioner merupakan salah satu jenis instrumen pengumpulan data dengan mendistribusikan angket untuk mendapatkan data primer dari responden.Menurut Pujihastuti (2010) kuesioner dapat didistribusikan dengan caralangsung oleh peneliti (mandiri), dikirim melalui pos (mailquestioner), dan dikirim dengan komputer (e-mail). Subjek penelitian merupakan penelitian individu, benda, atau organisme dimana penelitian ini dapat memberikan informasi yang dibutuhkan untuk data penelitian. Public Relations Grandia Hotel Bandung adalah sumber informan kami tentang peran public relations dalam industri perhotelan yang terkait dengan penelitian yang akan dilaksanakan. Kemudian untuk mendapatkan informasi tambahan, kami juga akanmengumpulkan data dari pegawai yang bekerja di hotel tersebut untuk menambahkan data di lapangan terkait pebgaruh yang diberikan oleh public relation didalam industri perhotelan.

Teknik pengumpulan data yang digunakan berupa purposive sampling, merupakan teknik pengambilan sampling berdasarkan karakteristik tertentu dalam suatu populasi yang memiliki hubungan dominan dengan sampel yang lainnya.Menurut Sugiyono (2010) purposive sampling merupakan teknik untuk menentukan sampel penelitian dengan beberapa pertimbangan tertentu yang bertujuan agar data yang diperoleh nantinya bisa lebih representatif.Grandia Hotel beserta staff didalamnya dapat menjadi responden yang baik dalam pengumpulan data dan informasi dalam penelitian ini, sehingga responden dapat memberikan informasi yang di butuhkan mengenai peran public relation di industri perhotelan. Data yang telah terkumpul kemudian diolahdengan mereduksi datayang dimbil dari lapangan. Kemudian setelah itu, peneliti akan menguraikan data dan mencoba untuk menjabarkan data tersebut dalam bentuk deskriptif yang selanjutnya akan diambil kesimpulan dari data tersebut.

\section{HASIL DAN PEMBAHASAN}

Sejarah Grandia Hotel dimulai pada tahun 1996, berasal dari membuat mie warisan keluarga, dengan gagasan baru membuat mie hijau (dari sari daun bayam), sehingga mulai dikenal di masyarakat bandung. Tahun 1997 Grandia mulai berdiri namun nama pertamanya adalah Grandies, berawal dari Bakery yang dibuat oleh ibu Lisye yang berawal dari donat, bolu kukus dan pisang molen setelah itu berkembang semakin banyak jenisnya. Tahun 2003 Tepatnya pada tanggal 8 Agustus 2003 Grandies berubah nama menjadi Grandia, tidak memakai nama Grandies berasal nama Grand (besar). Tahun 2004 mengembangkan diri dengan bisnis cafe dan resto, munculnya Grandia cafe and resto ini meramaikan wisata kuliner Bandung yang pada perkembangan selanjutnya, resto ini mulai menerima acara resesi pernikahan dan rapat-rapat pemerintahan. Tahun 2005 Dengan tim yang hanya 8 orang, Grandia mulai maju ke bisnis catering dan menawarkan rice box and snack box ke kantor pemerintahan, bank-bank, dan instansi lainnya. Pada tahun ini juga Grandia mencapai rekor tertinggi untuk menyiapkan sebanyak 1000 lunch box dan 1000 snack box untuk acara 17 agustus di Gedung Sate. Suksesnya catering ini memacu semangat Ibu Lisye untuk menawarkan catering ke luar kota, sehingga Grandia mulai dikenal pelanggan di luar kota, di kalangan pemerintahan. Diantaranya Telkom, Biofarma dll. Setiap kali ada catering keluar kota, Grandia selalu membawa peralatan dapur sampai 3 container, dan di setting seperti dapur yang ada di Grandia, walaupun ironis dan lucu tradisi ini selalu dilakukan untuk menjaga kualitas, rasa, dan kesegaran makanan. Sampai-sampai acara catering di 2 kota dilakukan dalam 2 hari berturut-turut dengan 2 kota yang berbeda. Misalnya Tasik dan Cianjur.Dengan semua kejadian sedih, ironis, dan lucu tetap membuat tim yang seadanya membuat semakin kompak dan solid.

Setelah 17 tahun Grandia Hotel berdiri, ada sosok Public Relations yang berperan penting di dalamnya.Public Relations di Grandia Hotel membawa kemajuan yang sangat pesat, dimulai dari bisnis Catering,Café and Resto,sehingga menjadi Grandia Hotel.Untuk membangun dan mencapai itu semua, peran Public Relations di Grandia Hotel di mulai dengan memanfaatkan wisatawan bandung yang berkunjung untuk kuliner. Setelah berjalannya waktu kini Public Relation di Grandia Hotel mempunyai kemajuan dan kami berkesempatan melakukan wawancara dengan salah satu Staff Public Relation di Grandia Hotel.

Kami menanyakan "Apa saja peran Public Relations di Grandia Hotel ?" peran Public Relations dapat dibagi menjadi dua, yaitu peranan managerial (communication manager role) dan peranan teknis (communication technical role). Hutapea (2000) menyatakan bahwa public relation adalah fungsi manajemen untuk membantu menegakan dan memelihara aturan bersama dalam komunikasi, demi terciptanya saling pengertian dan kerjasama antara perusahaan dengan publik, 
mengatur dan menekankan tanggung jawab dalam melayani kepentingan masyarakat. Peranan managerial dikenal dengan peranan di tingkat manajemen dapat diuraikan menjadi tiga peranan, yaitu expert preciber communication, problem solving process facilitator, dan communication facilitator. Bila dijelaskan lebih jauh terdapat 4 peranan, meliputi: 1. expert preciber communication, petugas PR dianggap sebagai orang yang ahli, dia menasihati pimpinan perusahaan atau organisasi, hubungan mereka diibaratkan seperti hubungan dokter dan pasien; 2. Problem solving process facilitator, peranan sebagai facilitator dalam proses pemecahan masalah. Pada peranan ini petugas humas melibatkan diri atau dilibatkan dalam setiap manajemen krisis, dia menjadi anggota tim, bahkan bila memungkinkan menjadi leader dalam penanganan krisis manajemen; 3 . Communication facilitator, peranan petugas humas sebagai facilitator komunikasi perusahaan atau organisasi dengan public, baik dengan publik eksternal maupun internal, istilah yang paling umum adalah sebagai jembatan komunikasi antara publik dengan perusahaan, sebagai media atau penengah bila terjadi miskomunikasi; 4. Technician communication, di sini petugas humas dianggap sebagai pelaksana teknis komunikasi, dia menyediakan layanan di bidang teknis, sementara kebijakan dan keputusan teknik komunikasi mana yang akan digunakan bukan merupakan keputusan petugas humas, melainkan keputusan manajemen dan petugas humas yang melaksanakannya, ucap Staff Public Relations Grandia Hotel.

Lalu kami menanyakanpertanyaan kedua yaitu "Apakah peran Public Relations di Industri Perhotelan sangat penting ?" lya sangat penting, jangankan di Industri Perhotelan di semua perusahaan apapun pasti peran Public Relations sangat penting dan sangat di butuhkan untuk membangun dan mencapai tujuan bersama. Public relation benar-benar merupakan fungsi manajemen, bertugas dengan penuh tanggung jawab menjaga reputasi suatu organisasi, membentuk, melindungi, dan memperkenalkannya (Rahadhini, 2012) seperti Grandia Hotel yang awal mulanya berdiri dengan nama Grandies dengan memproduksi bakery berkembang menjadi sebuah Hotel, selain pemiliknya, peran Public Relations pun berperan penting di dalamnya sehingga membawa kemajuan.

Dan kami menanyakan pertanyaan terakhir yaitu "Apa saja aktivitas peran Public Relations secara garis besar di Grandia Hotel ?"Berikut adalah aktivitas Public Relation secara garis besar di Grandia Hotel. 1. Mengkliping semua informasi dari surat kabar mengenai segala aktivitas dan informasi mengenai competitor hotel. 2. Mengadakan greeting dengan para tamu hotel pada saat sarapan pagi atau breakfast. 3. Mengundang para wartawan ke hotel baik cetak maupun elektronik dalam media gathering satu minggu sekali. 4. Mengikuti kegiaatan sales call atau sales promotion bersama staff marketing lainnya. 5. Mengadakan kunjungan- kunjungan ke media baik cetak maupun elektronik untuk menjalin hubungan yang baik dengan media. 6. Membuat siaran press(press release) produk hotel untuk kemudian dikrim ke media cetak. 7. Membuat resume guest comment mengenai komentar tamu yang ditujukan pada pelayanan hotel. 8. Mengambil foto(taking a picture) sebagai dokumen dan bahan press release yang dikirim ke media cetak. 9. Mengadakan koordinasi dengan art worker dan media dalam pembuatan design iklan, news letter, brosur, majalah dinding sebagai sarana komuikasi internal. 10. Mengikuti meeting Morning breefing dan konseling.Melihat dari banyaknya kegiatan yang dilakukan oleh public relation di Grandia Hotel menunjukan bahwa peran public relation sangat berpengaruh disuatu perusahaan. Melalui public relation inilah manajeman organisais melakukan aktivitas dan komunikasinya, baik itu kepada pihak internal seperti karyawan, manajemen dan publik eskternal seperti masyarakat sekitar dan konsumen (Ishak, 2012).

\section{KESIMPULAN}

Berdasarkan pembahasan diatas dapat disimpulkan bahwa industri perhotelan merupakan suatu industri yang bergerak dibidang pelayanan dan jasa. Dengan adanya public relation menjadikannya sebagai ujung tombak dalam bersaing di industri perhotelan. Karena public relation dapat menciptakan image positif untuk membangun citra baik dari suatu perusahaan. Berdasarkan penelitian yang kami lakukan, dapat disimpulkan bahwa peran public relation dibagi menjadi dua, yaitu peranan managerial (communication manager role)dan peranan teknis (communication technical role). Communication manager role meliputi pengaturan dan pengawasan suatu perusahaan, menciptakan komunikasi yang baik antara pihak internal maupun pihak eksternal, membuat solusi pemecahan masalah yang terjadi pada suatu perusahaan, dan menjalin citra baik antar perusahaan maupun kepada publik. Sedangkan communication technical role meliputi 
penyediaan layanan teknis dibidang komunikasi dan juga turut serta dalam menjalankan teknis komunikasi tersebut. Jadi, peran public relation dibidang industri perhotelan memegang peranan yang penting bahkan sangat dibutuhkan. Selain untuk menjaga nama baik perusahaan kepada publik, public relation juga memegang andil besar dari keberlangsungan suatu perusahaan yang bersangkutan, dengan menjaga komunikasi internal antara pihak atas dan pihak bawah serta menjadi problem solving yang dapat memberikan solusi dari masalah yang dihadapi suatu perusahaan.

\section{Referensi}

Anggito, A, dan Johan Setiawan. (2018). Metodologi Penelitian Kualitatif.Sukabumi : CV Jejak. Link : https://books.google.co.id/books?hl=id\&lr=\&id59V8DwAAQBAJ\&oi=fnd\&pg=PP1\&dg=info:3v9zzStyQ FYJ:scholar.google.com/\&ots=5HbxpCayEv\&sig=aCypM6CxnjhZLB7cmo1 ILu8jZM0\&redir_esc=y\#v= onepage \&q\& $\mathrm{f}=$ false .

Ghaniy, Sanaubar. 2017Pengaruh Potensi Pariwisata Terhadap Penyerapan Tenaga Kerja SektorPerhotelan Di 9 Kabupaten/Kota Provinsi Jawa Timur Tahun 2012-2015.Jurnal. IImu Ekonomi.

Herimanto, Bambang. 2007. Public Relation Dalam Organisasi (1 ed). Yogyakarta : Santusta.

Hutapea, 2000, Public Relation Sebagai Fungsi Manajemen. Majalah Widya, Agustus 2000, No. 179 Tahun XVII.

Ishak, Aswad. 2012. Peran Public Relations Dalam Komunikasi Organisai. Jurnal Aspikom 1 (4). Hal 1-8.

Nova.Firsan 2009. Crisis Public Relations.Jakarta : Grasindo

Pujihastuti, Isti. 2010. Prinsip Penulisan Kuesioner Penelitian. Vol. 2. No. 1. Hal 1-13. Link : https://scholar.google.com/scholar?hl=id\&as_sdt=0\%2C5\&q=metode+pengumpulan+data+kuesioner $\& 0 \mathrm{q}=$ metode+pengumpulan+data+kues\#d=gs_qabs\&u=\%23p\%3DvJodWFG36Ow .

Rahdhini, MD. 2012. Peran Public Relation Dalam Membangun Citra Perusahaan Melalui Program Corporate Social Responsibility. Jurnal Ekonomi dan Kewirausahaan. 10 (1). Hal 1-11. Link : https://scholar.google.com/scholar?hl=id\&as_sdt=0\%2C5\&q=peran+public+relation\&oq=peran+pub\# $d=g s \_q a b s \& u=\% 23 p \% 3 D Q S \_F 5 q j z W h l J$.

Rohim Syaiful. 2009. Teori Komunikasi.Jakarta : PT. Rineka Cipta.

Scott M Cultip \& Allen H Center.(2006). Effective Public Relation (Vol. 9). Jakarta: Kencana

Scott M Cultip \& Allen H Center.2006. Effective Public Relation. Vol. 9.Jakarta : Kencana

Wiryanto.2004. Pengantar IImu Komunikasi.Jakarta : PT. Gramedia Widasarana Indonesia. 